\title{
Enfermedad de MELAS en Latinoamérica: revisión temática.
}

\author{
MELAS in Latin America
}

\author{
Wilfor Aguirre-Quispe 1,a, Mariana Valdez-Taboada 1,a, Luis Urbina-Ramírez 1,b, Andrea Rivera- \\ Valdivia $^{1,2,3, b}$, Elison Sarapura-Castro ${ }^{1, b}$, Julio Montoya ${ }^{4,5, c}$, Mario Cornejo-Olivas ${ }^{1,6, b}$
}

\section{RESUMEN}

Revisión temática sobre la enfermedad de MELAS y casos reportados en Latinoamérica entre 1990 y 2021, mediante búsquedas en las bases de datos LILACs, Scielo, PubMed/Medline y Scopus. De un total de 966 publicaciones, se seleccionaron 19 reportes/series de casos y se describen 51 casos (39 niños y 12 adultos), 42 de ellos en ocho países latinoamericanos y con estudios genéticos. La variante m.3243A $>$ G fue la más frecuentemente identificada, con una edad media de $12 \pm 9.7$ años y un discreto predominio en mujeres. Las manifestaciones neurológicas más frecuentes fueron episodios de stroke like y epilepsia. Las lesiones más frecuentes detectadas por resonancia magnética fueron de tipo isquémico stroke like y calcificación de núcleos de la base.

PALABRAS CLAVE: Síndrome de MELAS, enfermedades mitocondriales, genes mitocondriales, Latinoamérica.

\section{SUMMARY}

A thematic review on MELAS in Latin America between 1990 and 2021 was conducted through a systematic literature search on LILACs, Scielo, PubMed/Medline and Scopus databases. Nineteen case reports/series out of 966 publications were selected and included 51 patients, 42 of them with genetic diagnosis reported in eight Latin American countries. The m.3243A $>\mathrm{G}$ variant was the most frequently reported, the mean age at onset being 12 \pm 9.7 years, with a mild female predominance. The most frequent neurological features were stroke-like episodes and seizures. Neuroimaging tests highlighted ischemic stroke-like lesions as well as calcified lesions in the basal ganglia.

KEYWORDS: MELAS syndrome, mitochondrial encephalomyopathies, mitochondrial diseases, mitochondrial genes.

\footnotetext{
Centro de Investigación Básica en Neurogenética, Instituto Nacional de Ciencias Neurológicas. Lima, Perú.

Fogarty Northern Pacific Global Health Fellows Program. Seattle, WA, United States.

Fogarty Interdisciplinary Cerebrovascular Diseases Training Program in South America. Lima, Perú.

Instituto de Investigaciones Sanitarias de Aragón (IISA), Universidad de Zaragoza. Zaragoza, España.

CIBERER, Universidad de Zaragoza. Zaragoza, España.

6 Centro de Salud Global, Universidad Peruana Cayetano Heredia. Lima, Perú.

a $\quad$ Médico Residente de Neurología; ${ }^{b}$ Médico Neurólogo; ${ }^{\mathrm{c}} \mathrm{PhD}$ en Ciencias
} 


\section{INTRODUCCION}

La encefalomiopatía mitocondrial, acidosis láctica y episodios stroke-like (episodios similares a enfermedad cerebrovascular), conocida como MELAS por su acrónimo en inglés (Mitochondrial encephalomyopathy with lactic acidosis and strokelike episodes), es un trastorno multisistémico progresivo causado por variantes genéticas en el ADN mitocondrial, considerada una enfermedad rara y huérfana (1-3). En 1982, se acuñó la denominación MELA para referirse a la Encefalopatía mitocondrial con acidosis láctica (4). En 1984, se presentaron las características clínicas distintivas de tres síndromes mitocondriales y se introduce por primera vez el acrónimo "MELAS" como un síndrome distintivo que incluye además a los episodios stroke-like (5).

Los pocos estudios de prevalencia regiónespecíficos, sugieren que la variante m.3243A> $\mathrm{G}$ en el gen MT-TL1, sería la más frecuentemente asociada a MELAS. En la región europea se estimó una frecuencia de esta variante entre 16-236/ 100000 habitantes adultos y se ha descrito una prevalencia en población infantil de 18.4/ $100000 \quad(6,7,9)$. En Japón se ha estimado una prevalencia global, incluyendo diversas variantes, en $0.18 / 100000$, siendo 0.50 (IC $95 \%, 0.41-0.59) / 100,000$ en menores de 18 años y 0.12 (IC $95 \%, 0.10-0.14) / 100,000$ en población adulta (10). En otros países, como España, se han descrito casos sin estimaciones poblacionales (11).

\section{MELAS en Latinoamérica}

No hemos encontrado estudios de prevalencia de MELAS en Latinoamérica, es por ello que realizamos una estrategia de búsqueda sistemática de las bases de datos LILACS/SciELO, PubMed/Medline y Scopus desde 1990 hasta el 30 de junio de 2021. La estrategia de búsqueda consistió en palabras clave como "MELAS Syndrome" y "MELAS", y otros términos relacionados ("m.3243A>G", "stroke like episodes"), restringiendo la búsqueda a países de Latinoamérica y el Caribe (Latin America, Hispanic, Central America, South America).

Los criterios de inclusión fueron: 1) reportes de casos o series de casos de Síndrome de MELAS en Latinoamérica; 2) publicaciones que describieron datos sociodemográficos y clínicos de los pacientes (incluyendo datos individuales o agregados); 3) diagnóstico genético de la enfermedad y 4) disponibilidad del texto completo o resúmenes en inglés o español. Se utilizó el programa Rayyan para seleccionar los estudios y eliminar duplicados. Posteriormente, dos autores (MVT \& WAQ) seleccionaron de forma independiente los informes y extrajeron los datos en Microsoft Excel.

\section{Evaluación de la calidad}

Utilizamos la herramienta propuesta por Murad et al.(12) Esta herramienta evalúa la calidad metodológica de los informes de casos/series evaluando 8 preguntas sobre cuatro dominios. Dado que nuestra revisión no se centra en los casos de eventos adversos, seleccionamos sólo 6 preguntas para nuestra evaluación: 1, 2, 3, 4, 7 y 8.

\section{Extracción de datos y sintesis narrativa}

Los datos fueron extraídos de forma independiente por dos autores (MVT y WAQ). Se extrajo la siguiente información: país, nombre del primer autor, año de

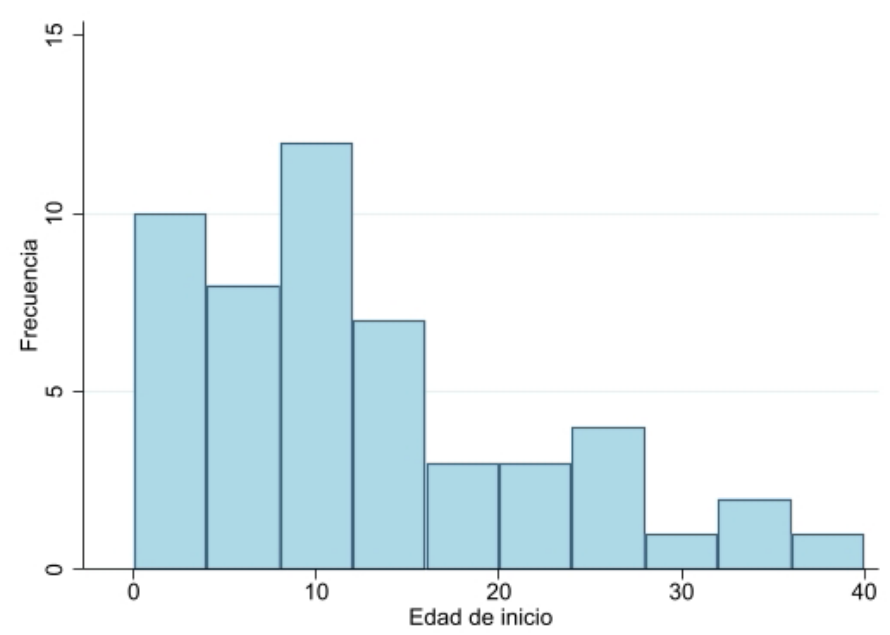

Gráfico 1. Distribución de la edad de inicio de los casos de MELAS 
publicación, sexo, edad de inicio, síntomas iniciales, cuadro clínico, resultados de ácido láctico, resultados de tomografía y resonancia magnética cerebral, biopsia muscular y estudio genético. Se describen las variables categóricas utilizando frecuencias y porcentajes, mientras que las numéricas como medianas y rangos intercuartílicos. Se utilizó el software Stata 17 (StataCorp. 2021. TX, USA). Se realizó un enfoque narrativo para sintetizar los estudios incluidos.

\section{RESULTADOS}

De los 966 estudios de la búsqueda global de las bases de datos utilizadas, únicamente 19 reportes de caso y series de caso fueron seleccionados. Un total de 51 casos con diagnóstico clínico de MELAS, 12 adultos y 39 niños, fueron descritos en las publicaciones incluidas; de estos, únicamente 42 (82\%) describen el estudio genético: 40 corresponden a la variante $\mathrm{m} .3243 \mathrm{~A}>\mathrm{G}, 1$ caso a la variante 13513 $\mathrm{G}>\mathrm{A}$ y 1 caso a la variante $3271 \mathrm{~T}>\mathrm{C}$. La edad media de inicio de la enfermedad es $12 \pm 9,7$ años, con un predominio en el sexo femenino (gráfico 1). Las manifestaciones neurológicas más frecuentes fueron los episodios de stroke like y epilepsia. Los episodios stroke like se presentaron en $66 \%(8 / 12)$ de adultos y $79 \%(31 / 39)$ en niños. La epilepsia se presentó en $42 \%$ de adultos (5/12) y $77 \%$ en niños (30/39) En neuroimágenes se evidenció principalmente lesiones isquémicas tipo stroke like y calcificación de núcleos basales. Lactacidemia y una biopsia positiva para fibras rojo-rasgadas fueron descritas en aproximadamente el $50 \%$ de casos. Estas características se resumen en la tabla 1.

Tabla 1. Características de casos de MELAS en Latinoamérica

\begin{tabular}{lc}
\hline Características & media \pm DS o n (\%) \\
\cline { 2 - 2 } Edad de inicio (años) & $12 \pm 9.7$ \\
\% Mujeres & $28(54.9)$ \\
\hline Manifestaciones neurológicas & \\
$\quad$ Episodios Stroke like & $39(76.4)$ \\
Epilepsia & $35(68.6)$ \\
Deterioro cognitivo & $13(25.4)$ \\
Alteración visual & $12(23.5)$ \\
Alteración auditiva & $12(23.5)$ \\
Cefalea & $11(21.5)$ \\
Talla baja & $5(9.8)$ \\
Ataxia & $3(5.8)$ \\
Encefalopatía & $3(5.8)$ \\
Intolerancia al ejercicio & $2(3.9)$ \\
Manifestaciones multisistémicas & \\
Gastrointestinales & $9(17.6)$ \\
Cardiacas & $6(11.7)$ \\
Musculares & $6(11.7)$ \\
Endocrinas & $5(9.8)$ \\
Psiquiátricas & $1(1.9)$ \\
Ácido láctico incrementado & \\
Sangre & $24(47.0)$ \\
LCR & $15(29.4)$ \\
Neuroimagenes & \\
Stroke like & $37(72)$ \\
Calcificación en núcleos basales & $14(27.4)$ \\
Ácido láctico elevado en la espectroscopia por resonancia magnética \\
Biopsia muscular & $4(7.8)$ \\
& $26(50.9)$ \\
\hline &
\end{tabular}


La revisión de la literatura en Latinoamérica mostró una cantidad reducida de casos de MELAS publicados. De estos no todos son casos confirmados con diagnóstico genético, siendo la mayoría de los reportes relacionados a la variante $\mathrm{m} .3243 \mathrm{~A}>\mathrm{G}$, lo cual limita el conocimiento de la distribución de las variantes relacionadas a esta enfermedad en Latinoamérica; sin embargo, se encontraron similitudes en cuanto a las características clínicas y diagnósticas (figura 1 y anexo 1).

\section{ETIOPATOGENIA}

La fisiopatología de la enfermedad no está completamente esclarecida; sin embargo, parte del fenotipo de la enfermedad puede ser explicada parcialmente por varios mecanismos que incluyen la producción de energía mitocondrial alterada, angiopatía de la microvasculatura y deficiencia de óxido nítrico (2).

\section{Alteraciones genéticas}

La enfermedad de MELAS es causada por variantes patogénicas en el ADN mitocondrial. En 1990 se describió por primera vez la variante $\mathrm{m} .3243 \mathrm{~A}>\mathrm{G}$ en el gen MT-TL1, que representa la causa genética de MELAS hasta en el $80 \%$ de los casos. Actualmente, se han descrito hasta 34 variantes patogénicas asociadas a MELAS en el gen MT-TL1 y otros genes mitocondriales implicados(1).

\section{Deficiencia energética y angiopatía}

Se ha visto que la variante $\mathrm{m} .3243 \mathrm{~A}>\mathrm{G}$ produce una traducción mitocondrial alterada con una disminución de la síntesis de proteínas mitocondriales afectando a las subunidades del complejo de la cadena trasportadora de electrones (CTE), y esto da como resultado una producción de energía mitocondrial deficiente $(13,14)$. La insuficiente generación de

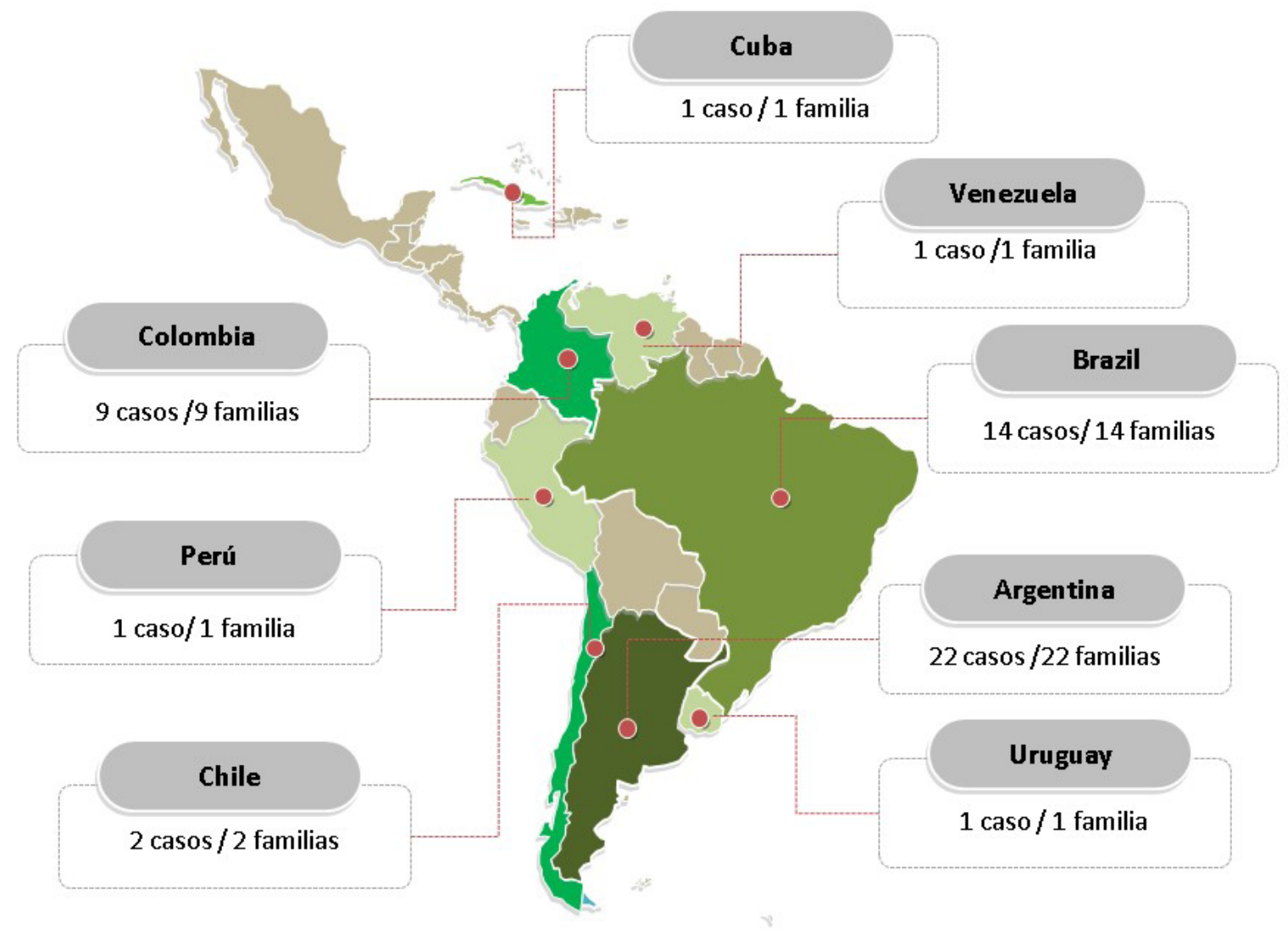

Figura 1. Distribución de casos de MELAS publicados en Latinoamérica. Los casos con diagnóstico genético descritos en Colombia fueron 26, sin embargo solo 9 de ellos (probandos de cada familia) tiene información clínica asociada. 
ATP para satisfacer las necesidades energéticas da como resultado la disfunción multiorgánica y una estimulación en la proliferación mitocondrial. La angiopatía debido a la proliferación mitocondrial en el músculo liso y las células endoteliales de los vasos sanguíneos pequeños conduce a una perfusión sanguínea alterada en la microvasculatura que contribuye significativamente a las complicaciones, específicamente a los episodios stroke like (2).

\section{Deficiencia de óxido nítrico (ON)}

Se ha planteado que la deficiencia de ON ocurre en el síndrome MELAS y puede contribuir significativamente a sus complicaciones $(15,16)$. El ON se forma a partir de la arginina a través de la enzima óxido nítrico sintasa, que cataliza la conversión de la arginina en citrulina. Tanto la citrulina como la arginina se consideran donantes de ON. El ON producido por el endotelio vascular desempeña un papel importante en la relajación del músculo liso vascular necesaria para mantener la permeabilidad de los vasos sanguíneos pequeños. Por tanto, la deficiencia de ON resulta en una alteración de la perfusión sanguínea en la microvasculatura de diferentes órganos que puede contribuir a la patogénesis de varias complicaciones(17). Se cree que la deficiencia de ON en el síndrome de MELAS es de origen multifactorial. La proliferación mitocondrial en las células endoteliales vasculares puede resultar en una función endotelial alterada y una síntesis de ON alterada. La sobreproducción de especies reactivas de oxígeno (estrés oxidativo) resultante de la alteración del CTE también puede disminuir la producción

Anexo 1. Casos de MELAS en Latinoamérica (Información complementaria):

\begin{tabular}{|c|c|c|c|c|c|c|c|c|}
\hline $\begin{array}{c}\text { País } \\
\text { (Autores) }\end{array}$ & Año & $\begin{array}{c}\text { Edad de } \\
\text { inicio/ } \\
\text { Sexo }\end{array}$ & Síntomas Iniciales & Cuadro clínico & $\begin{array}{c}\text { Ácido láctico } \\
\text { sérico/LCR }\end{array}$ & TC / RM encéfalo & $\begin{array}{c}\text { Biopsia } \\
\text { muscular }\end{array}$ & $\begin{array}{l}\text { Estudio } \\
\text { genético }\end{array}$ \\
\hline $\begin{array}{l}\text { Colombia } \\
\text { (Ramirez } \\
\text { et al) }\end{array}$ & 2016 & $23 / \mathrm{M}$ & $\begin{array}{l}\text { Cefalea, amaurosis, } \\
\text { stroke like }\end{array}$ & $\begin{array}{l}\text { Hipoacusia bilateral. } \\
\text { Deterioro cognitivo Atrofia } \\
\text { muscular generalizada } \\
\text { síntomas gastrointestinales }\end{array}$ & no/no & $\begin{array}{l}\text { Hipodensidad parietal } \\
\text { y occipital derecha/ } \\
\text { Hiperseñal T2 y } \\
\text { restricción a la difusión en } \\
\text { corteza occipitotemporal } \\
\text { derecha }\end{array}$ & No & $\mathrm{m} .3243 \mathrm{~A}>\mathrm{G}$ \\
\hline \multirow{3}{*}{$\begin{array}{l}\text { Brasil } \\
\text { (Conforto } \\
\text { et al) }\end{array}$} & \multirow{3}{*}{2007} & $27 / \mathrm{M}$ & Crisis epilépticas & encefalopatía, epilepsia & $\begin{array}{l}\text { incrementado / } \\
\text { incrementado }\end{array}$ & $\begin{array}{l}\text { No / lesiones temporo- } \\
\text { parieto-occipitales } \\
\text { derechas }\end{array}$ & $\mathrm{Si}$ & m. $3243 A>G$ \\
\hline & & $15 / F$ & Pérdida auditiva & $\begin{array}{l}\text { cefalea, pérdida de la } \\
\text { audición, epilepsia, episodios } \\
\text { stroke like, diabetes mellitus }\end{array}$ & $\begin{array}{l}\text { ligeramente } \\
\text { incrementado } \\
\text { / ligeramente } \\
\text { incrementado }\end{array}$ & $\begin{array}{l}\text { Calcificaciones en } \\
\text { globo pálido y pulvinar } \\
\text { bilaterales/ Hiperseñales } \\
\text { en T2 corticales temporo- } \\
\text { parietales derechas }\end{array}$ & $\mathrm{Si}$ & m. $3243 A>G$ \\
\hline & & $9 / \mathrm{M}$ & Crisis epilépticas & $\begin{array}{l}\text { Epilepsia, hemiparesia } \\
\text { derecha }\end{array}$ & $\begin{array}{l}\text { incrementado / } \\
\text { incrementado }\end{array}$ & $\begin{array}{l}\text { No / Hiperseñal T2 } \\
\text { en corteza temporal y } \\
\text { sustancia blanca bilateral }\end{array}$ & $\mathrm{Si}$ & m. $3243 \mathrm{~A}>\mathrm{G}$ \\
\hline $\begin{array}{l}\text { Chile } \\
\text { (Contreras } \\
\text { et al) }\end{array}$ & 2008 & $33 / F$ & Migraña sin aura & $\begin{array}{l}\text { Hipertensión arterial, afasia, } \\
\text { déficit visual, hemiparesia } \\
\text { derecha, } \\
\text { Hipoacusia bilateral }\end{array}$ & $\begin{array}{l}\text { incrementado / no } \\
\text { descrito }\end{array}$ & $\begin{array}{l}\text { Hipodensidad parieto- } \\
\text { occipital izquierda / } \\
\text { Hiperseñal en la corteza } \\
\text { parieto-occipital izquierda } \\
\text { y en am- } \\
\text { bos lóbulos temporales }\end{array}$ & $\mathrm{Si}$ & m. $3243 A>G$ \\
\hline $\begin{array}{l}\text { Perú } \\
\text { (Escalante } \\
\text { et al) }\end{array}$ & 2015 & $10 / \mathrm{F}$ & $\begin{array}{l}\text { Estado confusional, } \\
\text { cefalea, crisis } \\
\text { epiléptica }\end{array}$ & $\begin{array}{l}\text { Crisis epiléptica, hemiparesia } \\
\text { izquierda, cefalea, } \\
\text { vómitos, dolor abdominal, } \\
\text { alucinaciones visuales. } \\
\text { Talla baja }\end{array}$ & $\begin{array}{l}\text { incrementado / } \\
\text { incrementado }\end{array}$ & $\begin{array}{l}\text { Calcificación de ganglios } \\
\text { basales y encefalomalacia } \\
\text { parieto-occipital/ } \\
\text { Hiperseñal frontal, } \\
\text { parietal derecha y parieto- } \\
\text { occipital izquierda }\end{array}$ & No & $\mathrm{m} .3243 \mathrm{~A}>\mathrm{G}$ \\
\hline $\begin{array}{l}\text { Argentina } \\
\text { (Garcia } \\
\text { et al) }\end{array}$ & 2010 & $16 / \mathrm{M}$ & $\begin{array}{l}\text { vómitos, cefaleas, } \\
\text { síndrome } \\
\text { cerebeloso, } \\
\text { trastornos de } \\
\text { conciencia con } \\
\text { episodios de } \\
\text { desorientación } \\
\text { y excitación } \\
\text { psicomotriz y } \\
\text { diplopía, talla baja }\end{array}$ & $\begin{array}{l}\text { Crisis epilépticas } \\
\text { generalizadas con auras. } \\
\text { Hipoacusia bilateral }\end{array}$ & $\begin{array}{l}\text { Incrementado/ } \\
\text { incrementado }\end{array}$ & $\begin{array}{l}\text { Calcificaciones bilaterales } \\
\text { simétricas de ganglios } \\
\text { basales. } \\
\text { / Hiperintensidad en } \\
\text { T2 y FLAIR a nivel } \\
\text { córtico-subcortical } \\
\text { temporo-occipitales y, en } \\
\text { ambos centros ovales); } \\
\text { hipointensidad de la } \\
\text { sustancia gris y blanca. } \\
\text { Pico de lactato }\end{array}$ & $\mathrm{Si}$ & m. $3243 A>G$ \\
\hline
\end{tabular}


Enfermedad de MELAS en Latinoamérica: revisión temática.

Anexo 1 (cont). Casos de MELAS en Latinoamérica (Información complementaria):

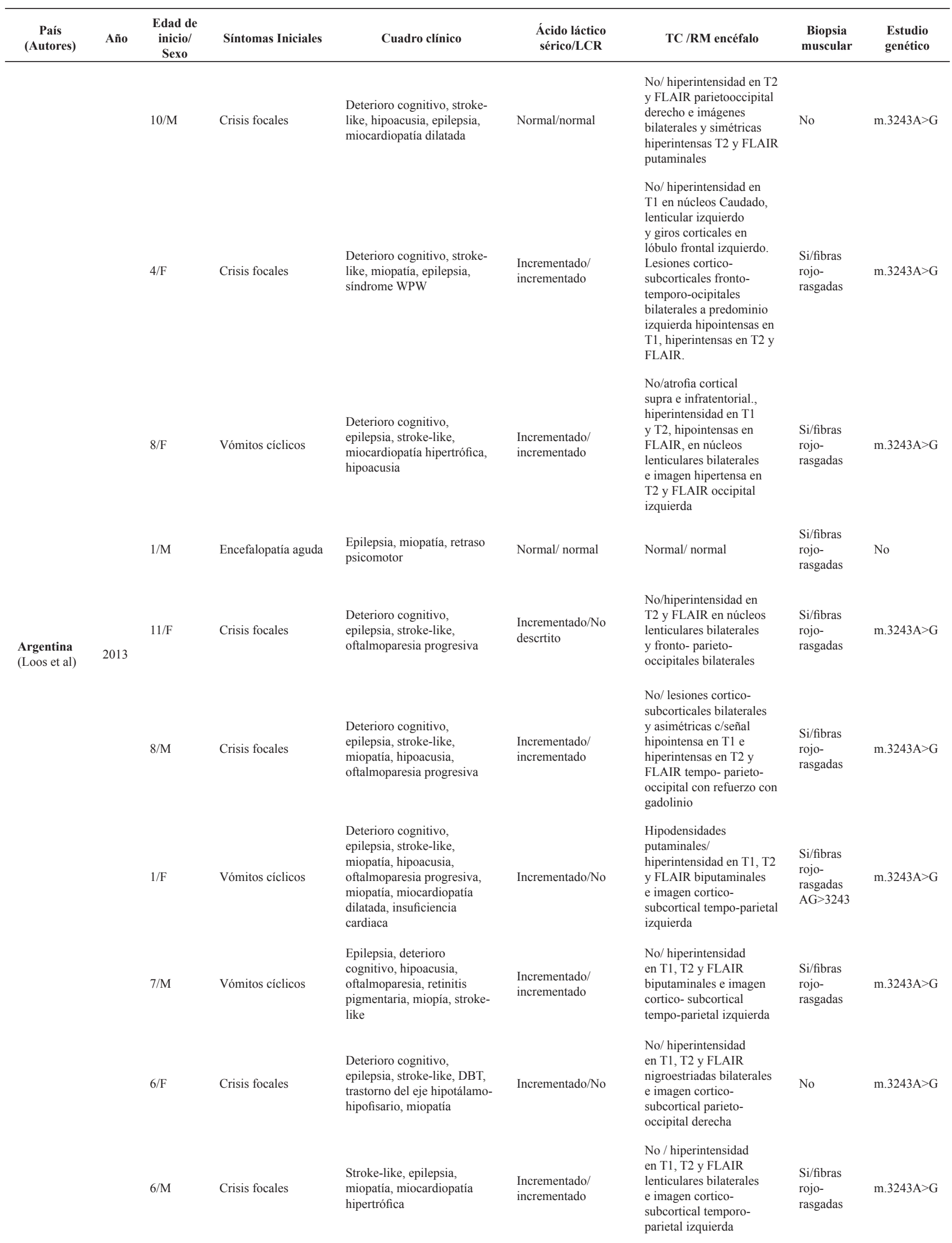


Aguirre-Quispe W, et al.

Anexo 1 (cont). Casos de MELAS en Latinoamérica (Información complementaria):

\begin{tabular}{|c|c|c|c|c|c|c|c|c|}
\hline $\begin{array}{c}\text { País } \\
\text { (Autores) }\end{array}$ & Año & $\begin{array}{c}\text { Edad de } \\
\text { inicio/ } \\
\text { Sexo }\end{array}$ & Síntomas Iniciales & Cuadro clínico & $\begin{array}{c}\text { Ácido láctico } \\
\text { sérico/LCR }\end{array}$ & TC / RM encéfalo & $\begin{array}{l}\text { Biopsia } \\
\text { muscular }\end{array}$ & $\begin{array}{l}\text { Estudio } \\
\text { genético }\end{array}$ \\
\hline \multirow[t]{2}{*}{$\begin{array}{l}\text { Colombia } \\
\text { (Granadillo } \\
\text { et al) }\end{array}$} & 2016 & $3 / \mathrm{F}$ & $\begin{array}{l}\text { marcha inestable y } \\
\text { talla baja }\end{array}$ & $\begin{array}{l}\text { Crisis epiléptica, episodio } \\
\text { de stroke like, pérdida } \\
\text { de la visión, hemiparesia } \\
\text { izquierda, ataxia de tronco, } \\
\text { hipotonia generalizada, } \\
\text { cefalea y vómitos }\end{array}$ & Elevado/- & $\begin{array}{l}\text { No / Infarto cerebral } \\
\text { temporo-occipital } \\
\text { Derecho. Espectroscopia: } \\
\text { área cortical } \\
\text { temporooccipital derecha } \\
\text { con } \\
\text { disminución de los picos } \\
\text { de N-acetilaspartato, } \\
\text { colina y creatina y un pico } \\
\text { dominante de lactato. }\end{array}$ & No & m. $3243 A>G$ \\
\hline & 2016 & $18 / \mathrm{M}$ & $\begin{array}{l}\text { Episodios de } \\
\text { Stroke like y crisis } \\
\text { epiléptica focal, } \\
\text { movimientos } \\
\text { mioclónicos }\end{array}$ & $\begin{array}{l}\text { Migraña recurrente, } \\
\text { disminución de agudeza } \\
\text { visual, vómitos recurrentes, } \\
\text { hernia hiatal, hipoacusia } \\
\text { neurosensorial bilateral }\end{array}$ & Elevado/- & $\begin{array}{l}\text { No / Múltiples infartos } \\
\text { cerebrales, de predominio } \\
\text { occipito-temporal basal } \\
\text { y me- } \\
\text { dial derecho; }\end{array}$ & No & m. $3271 \mathrm{~T}>\mathrm{C}$ \\
\hline $\begin{array}{l}\text { Venezuela } \\
\text { (Guevara) }\end{array}$ & 2007 & $\begin{array}{l}7 \\
\text { meses/F }\end{array}$ & Crisis epiléptica. & $\begin{array}{l}\text { Hipotonía axial, Hemiparesia } \\
\text { de recha postcrítica. Hiporre } \\
\text { flexia osteotendinosa en } \\
\text { miembros superiores e } \\
\text { inferiores. }\end{array}$ & Elevado/No & No / Normal & No & $\mathrm{m} .3243 \mathrm{~A}>\mathrm{G}$ \\
\hline \multirow[t]{5}{*}{$\begin{array}{l}\text { Uruguay } \\
\text { (Legnani) }\end{array}$} & 2016 & $32 / \mathrm{F}$ & $\begin{array}{l}\text { Crisis epiléptica } \\
\text { focal motora con } \\
\text { clonias de } \\
\text { hemicara y miembro } \\
\text { superior izquierdo }\end{array}$ & $\begin{array}{l}\text { Epilepsia, cefalea frontal, } \\
\text { fiebre, dolor abdominal, } \\
\text { vómitos y diarrea, }\end{array}$ & No & $\begin{array}{l}\text { Hipodensidad témporo- } \\
\text { parietal derecha } \\
\text { y calcificaciones } \\
\text { gangliobasales / Área } \\
\text { de isquemia aguda en } \\
\text { región cortico-subcortical } \\
\text { temporo-parietal } \\
\text { derecha }\end{array}$ & No & m. $3243 A>G$ \\
\hline & & $3 / \mathrm{F}$ & $\begin{array}{l}\text { Intolerancia al } \\
\text { ejercicio }\end{array}$ & $\begin{array}{l}\text { Episodios stroke like ( } 3 \\
\text { eventos), deterioro cognitivo, } \\
\text { epilepsia. Migraña, } \\
\text { oftalmoparesia }\end{array}$ & No & No & No & m. $3243 A>G$ \\
\hline & & $11 / \mathrm{M}$ & Episodios stroke like & $\begin{array}{l}\text { Episodios stroke like, } \\
\text { epilepsia, migraña }\end{array}$ & No & No & No & m. $3243 A>G$ \\
\hline & & $2 / \mathrm{M}$ & Debilidad muscular & $\begin{array}{l}\text { Episodios stroke like } \\
\text { (4), epilepsia, migraña, } \\
\text { compromiso cognitivo, } \\
\text { oftalmoparesia, signos } \\
\text { piramidales }\end{array}$ & No & No & No & m. $3243 A>G$ \\
\hline & & $12 / \mathrm{F}$ & Episodio stroke like & $\begin{array}{l}\text { Episodios stroke like ( } 3 \\
\text { eventos), compromise } \\
\text { cognitive, epilepsia, ataxia }\end{array}$ & No & No & No & m. $3243 A>G$ \\
\hline \multirow[t]{6}{*}{$\begin{array}{l}\text { Argentina } \\
\text { (Loos) }\end{array}$} & 2021 & $5 / \mathrm{F}$ & Pubertad precoz & $\begin{array}{l}\text { Episodios stroke like ( } 7 \\
\text { eventos), compromiso } \\
\text { cognitivo, epilepsia. } \\
\text { Migraña, oftalmoparesia }\end{array}$ & No & No & No & m. $3243 A>G$ \\
\hline & & $14 / \mathrm{F}$ & Episodio stroke like & $\begin{array}{l}\text { Episodios stroke like (2 } \\
\text { eventos), compromise } \\
\text { cognitive, epilepsia. }\end{array}$ & No & No & No & m. $3243 A>G$ \\
\hline & & $0 / \mathrm{F}$ & $\begin{array}{l}\text { Retraso en } \\
\text { desarrollo global }\end{array}$ & $\begin{array}{l}\text { Episodios stroke like, } \\
\text { compromise cognitive, } \\
\text { epilepsia }\end{array}$ & No & No & No & m. $3243 A>G$ \\
\hline & & $10 / \mathrm{F}$ & Episodio stroke like & $\begin{array}{l}\text { Episodios stroke like ( } 3 \\
\text { eventos), compromiso } \\
\text { cognitivo, epilepsia, signos } \\
\text { piramidales }\end{array}$ & No & No & No & m. $3243 A>G$ \\
\hline & & $0 / \mathrm{F}$ & $\begin{array}{l}\text { Retraso en } \\
\text { desarrollo global }\end{array}$ & Retraso en desarrollo global & No & No & No & m. $3243 A>G$ \\
\hline & & $10 / \mathrm{F}$ & Hipoiroidismo & $\begin{array}{l}\text { Episodios stroke like } \\
\text { cerebelares, compromiso } \\
\text { cognitivo, epilepsia, migraña, } \\
\text { signos piramidales }\end{array}$ & No & No & No & $\begin{array}{l}\mathrm{m} .13513 \\
\mathrm{G}>\mathrm{A}\end{array}$ \\
\hline
\end{tabular}


Enfermedad de MELAS en Latinoamérica: revisión temática.

Anexo 1 (cont). Casos de MELAS en Latinoamérica (Información complementaria):

\begin{tabular}{|c|c|c|c|c|c|c|c|c|}
\hline $\begin{array}{c}\text { País } \\
\text { (Autores) }\end{array}$ & Año & $\begin{array}{c}\text { Edad de } \\
\text { inicio/ } \\
\text { Sexo }\end{array}$ & Síntomas Iniciales & Cuadro clínico & $\begin{array}{l}\text { Ácido láctico } \\
\text { sérico/LCR }\end{array}$ & TC /RM encéfalo & $\begin{array}{l}\text { Biopsia } \\
\text { muscular }\end{array}$ & $\begin{array}{l}\text { Estudio } \\
\text { genético }\end{array}$ \\
\hline \multirow[t]{6}{*}{$\begin{array}{l}\text { Colombia } \\
\text { (López } \\
\text { et al) }\end{array}$} & 2020 & $5 / \mathrm{F}$ & $\begin{array}{l}\text { epilepsia focal, } \\
\text { ataxia }\end{array}$ & $\begin{array}{l}\text { deterioro neurológico } \\
\text { progresivo, disminución de } \\
\text { la fuerza muscular, marcha } \\
\text { atáxica, mutismo y falta de } \\
\text { seguimiento visual }\end{array}$ & $\begin{array}{l}\text { Incrementado/ } \\
\text { incrementado }\end{array}$ & $\begin{array}{l}\text { lesión sugestiva de infarto } \\
\text { cerebral en el lóbulo } \\
\text { occipital derecho/T1 } \\
\text { mostró hipointensidad } \\
\text { cortico-subcortical } \\
\text { temporo-occipital } \\
\text { derecha con leve efecto } \\
\text { compresivo sobre la } \\
\text { línea media y el cuerno } \\
\text { occipital del ventrículo } \\
\text { lateral ipsilateral }\end{array}$ & No & m. $3243 \mathrm{~A}>\mathrm{G}$ \\
\hline & & $12 / \mathrm{M}$ & & $\begin{array}{l}\text { Episodios stroke-like, } \\
\text { vómitos, cefalea, crisis, } \\
\text { debilidad, }\end{array}$ & Incrementado/No & $\begin{array}{l}\text { Afectación temporo- } \\
\text { occipital bilateral/- }\end{array}$ & $\begin{array}{l}\mathrm{Si} / \text { fibras } \\
\text { rojo- } \\
\text { rasgadas }\end{array}$ & No \\
\hline & & $22 / \mathrm{F}$ & & $\begin{array}{l}\text { Episodios stroke-like, } \\
\text { vómitos, cefalea, crisis, }\end{array}$ & $\mathrm{No} / \mathrm{No}$ & $\begin{array}{l}\text { Afectación fronto- } \\
\text { temporal derecha/- }\end{array}$ & $\begin{array}{l}\mathrm{Si} / \text { fibras } \\
\text { rojo- } \\
\text { rasgadas }\end{array}$ & No \\
\hline & & $9 / \mathrm{M}$ & & $\begin{array}{l}\text { Episodios stroke-like, } \\
\text { vómitos, cefalea, crisis, } \\
\text { pérdida auditiva, ataxia }\end{array}$ & Incrementado/No & $\begin{array}{l}\text {-/ calcificación ganglios } \\
\text { basales bilaterales }\end{array}$ & $\begin{array}{l}\mathrm{Si} / \text { fibras } \\
\text { rojo- } \\
\text { rasgadas }\end{array}$ & No \\
\hline & & $3 / \mathrm{M}$ & & $\begin{array}{l}\text { Retraso del desarrollo, } \\
\text { episodios stroke-like, } \\
\text { vómitos, cefalea, crisis }\end{array}$ & Incrementado/No & $\begin{array}{l}\text { Temporo-occipital } \\
\text { izquierda/- }\end{array}$ & $\begin{array}{l}\mathrm{Si} / \text { fibras } \\
\text { rojo- } \\
\text { rasgadas }\end{array}$ & No \\
\hline & & $4 / F$ & & $\begin{array}{l}\text { Episodios stroke-like, } \\
\text { vómitos, neuropatía facial }\end{array}$ & Incrementado/No & -/ occipital bilateral & $\begin{array}{l}\mathrm{Si} / \text { fibras } \\
\text { rojo- } \\
\text { rasgadas }\end{array}$ & No \\
\hline \multirow[t]{5}{*}{$\begin{array}{l}\text { Brasil } \\
\text { (Lorenzoni } \\
\text { et al) }\end{array}$} & 2009 & $15 / \mathrm{F}$ & & $\begin{array}{l}\text { Episodios stroke-like, } \\
\text { vómitos, cefalea, crisis, } \\
\text { debilidad, demencia }\end{array}$ & Incrementado/No & $\begin{array}{l}\text { Temporo- parieto- } \\
\text { occipital izquierdo/No }\end{array}$ & $\begin{array}{l}\mathrm{Si} / \text { fibras } \\
\text { rojo- } \\
\text { rasgadas }\end{array}$ & m. $3243 \mathrm{~A}>\mathrm{G}$ \\
\hline & & $14 / \mathrm{M}$ & & $\begin{array}{l}\text { Episodios stroke-like, } \\
\text { vómitos, cefalea, crisis, } \\
\text { debilidad, demencia, pérdida } \\
\text { auditiva, talla corta, síntomas } \\
\text { oculares }\end{array}$ & $\begin{array}{l}\text { Incrementado/ } \\
\text { incrementado }\end{array}$ & $\begin{array}{l}\text { No/ Temporo- parieto- } \\
\text { occipital izquierdo }\end{array}$ & $\begin{array}{l}\mathrm{Si} / \text { fibras } \\
\text { rojo- } \\
\text { rasgadas }\end{array}$ & m. $3243 A>G$ \\
\hline & & $8 / \mathrm{M}$ & & $\begin{array}{l}\text { Episodios stroke-like, } \\
\text { vómitos, cefalea, crisis, } \\
\text { debilidad, demencia }\end{array}$ & $\begin{array}{l}\text { Incrementado/ } \\
\text { normal }\end{array}$ & $\begin{array}{l}\text { No/Fronto- parieto- } \\
\text { temporal bilateral }\end{array}$ & $\begin{array}{l}\mathrm{Si} / \text { fibras } \\
\text { rojo- } \\
\text { rasgadas }\end{array}$ & m. $3243 A>G$ \\
\hline & & $25 / \mathrm{F}$ & & $\begin{array}{l}\text { Episodios stroke-like, } \\
\text { vómitos, debilidad, } \\
\text { demencia, síntomas oculares }\end{array}$ & Normal/No & No/cerebelo derecho & $\begin{array}{l}\mathrm{Si} / \text { fibras } \\
\text { rojo- } \\
\text { rasgadas }\end{array}$ & No \\
\hline & & $27 / \mathrm{M}$ & & $\begin{array}{l}\text { Episodios stroke-like, } \\
\text { vómitos, cefalea, debilidad, } \\
\text { demencia, pérdida auditiva, } \\
\text { talla corta, síntomas oculares }\end{array}$ & Incrementado/No & $\begin{array}{l}\text { No/ calcificación ganglios } \\
\text { basales izquierdos }\end{array}$ & $\begin{array}{l}\mathrm{Si} / \text { fibras } \\
\text { rojo- } \\
\text { rasgadas }\end{array}$ & $\mathrm{m} .3243 \mathrm{~A}>\mathrm{G}$ \\
\hline $\begin{array}{l}\text { Brasil } \\
\text { (Luchesi } \\
\text { et al) }\end{array}$ & 2018 & $26 / F$ & - & $\begin{array}{l}\text { Debilidad generalizada, } \\
\text { somnolencia diurna, disartria } \\
\text { flácida, disfagia progresiva }\end{array}$ & No & No & No & No descrito \\
\hline $\begin{array}{l}\text { Argentina } \\
\text { (Padin et al) }\end{array}$ & 2015 & $29 / \mathrm{M}$ & Crisis epilépticas & $\begin{array}{l}\text { Cefalea, epilepsia, alteración } \\
\text { conciencia }\end{array}$ & Incrementado/No & $\begin{array}{l}\text { hipodensidad cortico- } \\
\text { subcortical a nivel } \\
\text { temporo- parieto-occipital } \\
\text { del lado izquierdo y } \\
\text { temporo-parietal derecho/ } \\
\text { Lesiones cortico- } \\
\text { subcorticales a nivel } \\
\text { temporo- parieto-occipital } \\
\text { del lado izquierdo y } \\
\text { temporo-parietal del lado } \\
\text { derecho, calcificaciones } \\
\text { en los ganglios de la base. }\end{array}$ & No & No \\
\hline
\end{tabular}


Aguirre-Quispe W, et al.

Anexo 1 (cont). Casos de MELAS en Latinoamérica (Información complementaria):

\begin{tabular}{|c|c|c|c|c|c|c|c|c|}
\hline $\begin{array}{c}\text { País } \\
\text { (Autores) }\end{array}$ & Año & $\begin{array}{c}\text { Edad de } \\
\text { inicio/ } \\
\text { Sexo }\end{array}$ & Síntomas Iniciales & Cuadro clínico & $\begin{array}{l}\text { Ácido láctico } \\
\text { sérico/LCR }\end{array}$ & TC /RM encéfalo & $\begin{array}{l}\text { Biopsia } \\
\text { muscular }\end{array}$ & $\begin{array}{l}\text { Estudio } \\
\text { genético }\end{array}$ \\
\hline \multirow[b]{2}{*}{$\begin{array}{l}\text { Colombia } \\
\text { (Parra et al) }\end{array}$} & & $6 / \mathrm{M}$ & $\begin{array}{l}\text { Cambios } \\
\text { comportamiento, } \\
\text { anorexia, cefalea, } \\
\text { fiebre, vómitos, } \\
\text { estado epiléptico } \\
\text { focal motor } \\
\text { repetidos, ataxia }\end{array}$ & $\begin{array}{l}\text { Crisis epiléptica focales con } \\
\text { generalización, dispraxia } \\
\text { construccional, }\end{array}$ & Incrementado/No & No & $\mathrm{Si}$ (normal) & $\mathrm{m} .3243 \mathrm{~A}>\mathrm{G}$ \\
\hline & 2009 & $8 / \mathrm{M}$ & $\begin{array}{l}\text { Cefalea hemicránea, } \\
\text { episodios stroke like }\end{array}$ & $\begin{array}{l}\text { Cefalea, parestesias, } \\
\text { disestesias, crisis epilépticas } \\
\text { clónicas, hemiparesia } \\
\text { izquierda, deterioro } \\
\text { neurológico, papiledema, } \\
\text { muerte }\end{array}$ & Incrementado/No & $\begin{array}{l}\text { Hernia subfacial izquierda } \\
\text { con edema del hemisferio } \\
\text { derecho, realce giriforme } \\
\text { y colapso del sistema } \\
\text { ventricular/infarto } \\
\text { en territorio de ACM } \\
\text { derecha con colapso } \\
\text { ventricular y desviación } \\
\text { de la línea media en } \\
\text { región parietal izquierda } \\
\text { zona hipointensa en T1 } \\
\text { e hiperintensa en T2 con } \\
\text { aumento del sistema } \\
\text { ventricular compatible } \\
\text { con infarto antiguo }\end{array}$ & No & m. $3243 \mathrm{~A}>\mathrm{G}$ \\
\hline \multirow[t]{2}{*}{$\begin{array}{l}\text { Colombia } \\
\text { (Patiño et al) }\end{array}$} & 2012 & $14 / \mathrm{F}$ & $\begin{array}{l}\text { Epilepsia, } \\
\text { migraña con aura, } \\
\text { intolerancia al } \\
\text { ejercicio, talla baja }\end{array}$ & $\begin{array}{l}\text { mov. involuntarios, crisis } \\
\text { epilépticas tónico -clónicas, } \\
\text { alteración conciencia }\end{array}$ & $\begin{array}{l}\text { incrementando/ } \\
\text { incrementado }\end{array}$ & $\begin{array}{l}\text { no/en FLAIR Imagen } \\
\text { hiperintensa cortico- } \\
\text { subcorticalque } \\
\text { delimita los surcos y } \\
\text { no se representa en las } \\
\text { secuencias de DWI y } \\
\text { ADC; espectroscopia } \\
\text { de la misma lesión que } \\
\text { muestra disminución de } \\
\text { N-Acetyl-Aspartato por } \\
\text { pérdida neuronal. }\end{array}$ & no & m. $3243 \mathrm{~A}>\mathrm{G}$ \\
\hline & & $19 / \mathrm{M}$ & $\begin{array}{l}\text { Intolerancia al } \\
\text { ejercicio/cefalea }\end{array}$ & $\begin{array}{l}\text { hemianopsia temporal } \\
\text { derecha, crisis epiléptica } \\
\text { clónica, hemiparesia } \\
\text { izquierda }\end{array}$ & $\begin{array}{l}\text { incrementado/ } \\
\text { incrementado }\end{array}$ & $\begin{array}{l}\text { No / FLAIR imagen } \\
\text { hiperintensa cortico } \\
\text { subcortical que delimita } \\
\text { los surcos, que se } \\
\text { restringe en la DWI, } \\
\text { pero no se representa en } \\
\text { el ADC. }\end{array}$ & no & $\mathrm{Si}$ \\
\hline $\begin{array}{l}\text { Colombia } \\
\text { (Romero } \\
\text { et al) }\end{array}$ & 2017 & $40 / F$ & $\begin{array}{l}\text { recortes } \\
\text { campimétricos } \\
\text { izquierdos, } \\
\text { dificultad en } \\
\text { ejecución } \\
\text { de acciones, } \\
\text { hemiparesia } \\
\text { izquierda }\end{array}$ & $\begin{array}{l}\text { Desorientación, irritabilidad, } \\
\text { lenguaje incoherente }\end{array}$ & $\begin{array}{l}\text { Incrementado/ } \\
\text { incrementado }\end{array}$ & $\begin{array}{l}\text { Hipodensidad cortico- } \\
\text { subcortical temporal, } \\
\text { parietal y occipital } \\
\text { izquierda, calcificaciones } \\
\text { ganglios basales y / } \\
\text { T2 y FLAIR extensa } \\
\text { lesión hiperintensa de } \\
\text { predominio cortical en } \\
\text { región parieto - temporo } \\
\text { - occipital izquierda } \\
\text { sin respetar territorio } \\
\text { vascular. Picos de lactato }\end{array}$ & $\mathrm{Si} /$ normal & $\mathrm{m} .3243 \mathrm{~A}>\mathrm{G}$ \\
\hline $\begin{array}{l}\text { Chile/ (Ruiz } \\
\text { et al) }\end{array}$ & 2013 & $+/-21 / F$ & $\begin{array}{l}\text { intolerancia al } \\
\text { ejercicio, debilidad, } \\
\text { migraña sin aura, } \\
\text { parestesias, talla } \\
\text { baja }\end{array}$ & $\begin{array}{l}\text { cefalea persistente, náuseas, } \\
\text { vómitos, parestesias e } \\
\text { hipoestesia }\end{array}$ & $\begin{array}{l}\text { incrementado/ } \\
\text { incrementado }\end{array}$ & $\begin{array}{l}\text { Hipodensidad temporo- } \\
\text { parietal derecha/ } \\
\text { aumento de señal } \\
\text { predominantemente } \\
\text { cortical Hiperintensidad } \\
\text { en lóbulo temporal y parte } \\
\text { parietal derecha }\end{array}$ & $\begin{array}{l}\mathrm{Si} / \text { fibras } \\
\text { rojas } \\
\text { rasgadas } \\
\text { aisladas }\end{array}$ & No \\
\hline
\end{tabular}


Enfermedad de MELAS en Latinoamérica: revisión temática.

Anexo 1 (cont). Casos de MELAS en Latinoamérica (Información complementaria):

\begin{tabular}{|c|c|c|c|c|c|c|c|c|}
\hline $\begin{array}{c}\text { País } \\
\text { (Autores) }\end{array}$ & Año & $\begin{array}{c}\text { Edad de } \\
\text { inicio/ } \\
\text { Sexo } \\
\end{array}$ & Síntomas Iniciales & Cuadro clínico & $\begin{array}{l}\text { Ácido láctico } \\
\text { sérico/LCR }\end{array}$ & TC / RM encéfalo & $\begin{array}{l}\text { Biopsia } \\
\text { muscular }\end{array}$ & $\begin{array}{l}\text { Estudio } \\
\text { genético }\end{array}$ \\
\hline $\begin{array}{l}\text { Cuba/ (Vargas } \\
\text { et al) }\end{array}$ & 2017 & $2 / \mathrm{M}$ & $\begin{array}{l}\text { Intolerancia al } \\
\text { ejercicio, talla baja }\end{array}$ & $\begin{array}{l}\text { efalea, amaurosis fugaz, } \\
\text { diarreas, vómitos, fiebre, } \\
\text { deterioro cognitivo, } \\
\text { crisis epiléptica focal y } \\
\text { generalizada, hemiparesia } \\
\text { derecha }\end{array}$ & $\begin{array}{l}\text { incrementado/ } \\
\text { incrementado }\end{array}$ & $\begin{array}{l}\text { Imagen sugestiva de } \\
\text { infarto cerebral isquémico } \\
\text { extenso, con compromiso } \\
\text { de los lóbulos parietal, } \\
\text { temporal y occipital } \\
\text { izquierdos/hiperintensidad } \\
\text { en los lóbulos parietal } \\
\text { posterior, occipital y } \\
\text { temporal izquierdos, que } \\
\text { no se corresponden con } \\
\text { un territorio vascular } \\
\text { específico, así como } \\
\text { hiperintensidad a nivel } \\
\text { del pulvinar ipsilateral } \\
\text { (signo del pulvinar) } \\
\text { y calcificaciones en } \\
\text { ganglios basales }\end{array}$ & $\begin{array}{l}\mathrm{Si} / \text { fibras } \\
\text { rojas } \\
\text { rasgadas }\end{array}$ & No \\
\hline
\end{tabular}

de $\mathrm{ON}(18)$. La lactacidemia es el resultado de la incapacidad de las mitocondrias disfuncionales para oxidar adecuadamente la glucosa, lo que lleva a la acumulación de piruvato y derivación de piruvato a lactato (19). Además, la hipoperfusión puede provocar acidosis láctica debido a la disminución del suministro de oxígeno a los tejidos periféricos y un cambio a la glucólisis anaeróbica. La deficiencia de $\mathrm{ON}$ en el síndrome de MELAS puede resultar en una disminución de la perfusión sanguínea y, por lo tanto, puede agravar la acidosis láctica (17).

\section{CUADRO CLÍNICO}

La enfermedad de MELAS es un trastorno multisistémico que se presenta en todos los grupos etarios. La mayoría de los casos de MELAS se encuentran entre 2-40 años, con más de la mitad de los casos con inicio de síntomas antes de los 20 años (2). Sin embargo, existen casos de presentación tardía después de los 40 años (20). La variabilidad fenotípica en MELAS se explica por: 1) la heteroplasmia, coexistencia de ADN mitocondrial normal y mutado. 2) La distribución variable del ADN mitondrial mutado en los tejidos y 3) la respuesta variable de cada tejido corporal al estrés oxidativo.

Las manifestaciones clínicas de MELAS se describen en la tabla 2. Las formas juveniles y las del adulto cursan con episodios similares a enfermedad cerebrovascular o stroke-like, cefaleas recurrentes y epilepsia $(2,10)$. Hirano observó 6 manifestaciones cardinales: stroke-like, crisis epilépticas, acidosis láctica, fibras rojo rasgadas, intolerancia al ejercicio y comienzo de los síntomas antes de los 40 años en más del $90 \%$ de los 110 casos reportados (21). En las formas juveniles de MELAS predominan la baja estatura y el retraso en el crecimiento, mientras que en la forma adulta diabetes mellitus y pérdida auditiva (10).

Los episodios stroke-like son uno de los síntomas más frecuentes de la enfermedad. Son episodios habitualmente reversibles de afasia, pérdida de visión cortical, debilidad motora, cefalea, crisis o alteración del estado mental; sin embargo, se han descrito formas progresivas de déficit neurológico(19).

La miopatía es frecuente en pacientes enfermedad mitocondrial incluyendo MELAS (22). Esta se presenta como intolerancia al ejercicio en un 73$100 \%$ y la debilidad muscular proximal en $42-89 \%$ $(10,19,21)$.

Las crisis epilépticas se presentan hasta en un 71$96 \%$, pueden ser focales o generalizadas, episodios aislados o en el contexto de un episodio stroke-like (23). La cefalea recurrente se presenta entre 54$91 \%(10,19,21)$. La cefalea suele ser más intensa al asociarse a episodios de stroke-like (24).La neuropatía periférica es otra manifestación común que ocurre en $22-77 \%$. La neuropatía axonal o axonal mixta y desmielinizante es el tipo más común $(25,26)$. La demencia suele presentarse entre 40-90\% $(10,21)$. Esta afecta principalmente el lenguaje, la memoria y percepción visuoespacial(19).

La enfermedad de MELAS habitualmente se asocia a varios síntomas extraneurológicos. Se ha observado compromiso cardíaco tanto miocardiopatía dilatada como hipertrófica; sin embargo, la más típica es una miocardiopatía hipertrofia concéntrica no obstructiva (19). Se han descrito también anomalías en la conducción cardiaca como el síndrome de 
Tabla 2. Manifestaciones iniciales y cuadro clínico en MELAS

\begin{tabular}{|c|c|c|c|}
\hline \multicolumn{2}{|r|}{ Síntomas iniciales (debut) } & \multicolumn{2}{|r|}{ Cuadro clínico } \\
\hline Frecuencia & Manifestaciones & Frecuencia & Manifestaciones \\
\hline$>25 \%$ & $\begin{array}{l}\text { Crisis epilépticas } \\
\text { Cefalea recurrente } \\
\text { Episodios stroke like } \\
\text { Pérdida de visión cortical } \\
\text { Debilidad muscular } \\
\text { Vómitos recurrentes } \\
\text { Baja estatura }\end{array}$ & $>90 \%$ & $\begin{array}{l}\text { Ictus } \\
\text { Demencia } \\
\text { Epilepsia } \\
\text { Acidemia láctica } \\
\text { Fibras rojo-rasgadas (en musculo } \\
\text { esquelético) }\end{array}$ \\
\hline $10-24 \%$ & $\begin{array}{l}\text { Alteración de conciencia } \\
\text { Pérdida de audición } \\
\text { Diabetes }\end{array}$ & $75-89 \%$ & $\begin{array}{l}\text { Hemiparesia } \\
\text { Ceguera cortical } \\
\text { Cefalea } \\
\text { Déficit auditivo } \\
\text { Intolerancia al ejercicio } \\
\text { Debilidad muscular }\end{array}$ \\
\hline$<10 \%$ & $\begin{array}{l}\text { Retraso en el desarrollo } \\
\text { Fiebre }\end{array}$ & $50-74 \%$ & $\begin{array}{l}\text { Neuropatía periférica } \\
\text { Alteración memoria } \\
\text { Vómitos cíclicos } \\
\text { Talla baja }\end{array}$ \\
\hline
\end{tabular}

Tomado y adaptado de El-Hattab et al, 2015 (2)

Wolff- Parkinson-White que se presenta en 13-27\%. (27). A nivel gastrointestinal, se ha descrito vómitos recurrentes hasta en un 77\% de casos; así como diarrea, estreñimiento, dismotilidad gástrica $(19,21,28)$. La presencia de diabetes en MELAS se ha descrito hasta en 33\% de los casos $(10,19)$. Algunos estudios sugieren una asociación entre la variante m.3243A> G y una mayor ocurrencia de diabetes mellitus (29). Se postula que el fracaso en la secreción de insulina por las células $\beta$ pancreáticas sería el mecanismo desencadenante de diabetes, posiblemente debido a un fallo de energía y la dependencia de estas células de bombas de sodio-potasio impulsadas por ATP $(19,29)$. En la diabetes mellitus no insulino dependiente se debe evitar el uso de metformina debido a que éste fármaco causa acidosis láctica (19). Se ha descrito síntomas psiquiátricos asociados a MELAS incluyendo trastornos del ánimo, psicosis y ansiedad (30).

\section{DIAGNÓSTICO}

\section{Diagnóstico clínico de MELAS}

El diagnóstico clínico de MELAS ha variado en el tiempo, desde que se describió por primera vez. Se han publicado dos conjuntos de criterios, los primeros fueron dados por Hirano en 1992 al analizar 69 reportes de caso (4). En 2012 se plantearon nuevos criterios diagnósticos dados por el comité de estudio de MELAS en Japón (10), que establece el diagnóstico clínico definitivo de MELAS con dos criterios pertenecientes a la categoría A y dos criterios de la categoría B; y sospecha de MELAS con un criterio de la categoría A y dos criterios de la categoría B (tabla 3).

\section{Estudios paraclínicos de apoyo diagnóstico}

\section{Neuroimágenes}

El uso de imágenes en MELAS tiene mayor utilidad durante los episodios agudos de la enfermedad. La tomografía cerebral ha sido muy utilizada inicialmente en los cuadros agudos de stroke-like. Los hallazgos más frecuentes en neuroimagen en MELAS incluyen la calcificación de núcleos basales bilaterales y tálamos. Se han descrito también, áreas corticales de hipodensidad localizadas en uno o ambos polos occipitales no confinadas a un territorio vascular; la afectación es habitualmente cortical (31).

Las imágenes por resonancia magnética ponderadas por difusión (DWI) son útiles en MELAS. A pesar de que habitualmente son utilizadas para evidenciar lesiones isquémicas, también resultan útiles en otras lesiones no isquémicas que pueden mimetizar un infarto como las patologías por enfermedad mitocondrial. A diferencia de un infarto habitual, en los episodios de stroke-like se plantea una superposición temporal del edema citotóxico inicial en la fase aguda 
Tabla 3. Criterios Diagnósticos de MELAS (10)

\begin{tabular}{|c|c|}
\hline $\begin{array}{l}\text { Categoría A } \\
\text { (Hallazgos de episodios stroke } \\
\text { like) }\end{array}$ & $\begin{array}{l}\text { 1. Dolores de cabeza con vómitos } \\
\text { 2. Crisis epiléptica } \\
\text { 3. Hemiplejía } \\
\text { 4. Ceguera cortical o hemianopsia } \\
\text { 5. Lesión focal aguda observada en neuroimagen (Tomografía cerebral y/o } \\
\text { resonancia magnética) }\end{array}$ \\
\hline $\begin{array}{l}\text { Categoría B } \\
\text { (Evidencia de disfunción } \\
\text { mitocondrial) }\end{array}$ & $\begin{array}{l}\text { 1. Niveles elevados de lactato en plasma y/o LCR } \\
\text { 2. Anomalías mitocondriales en la biopsia muscular } \\
\text { 3. Variante patogénica relacionada con MELAS }\end{array}$ \\
\hline
\end{tabular}

Tomado y adaptado de Yatsuga et al, 2012 (10)

y el edema vasogénico en la fase subaguda a crónica de las lesiones, lo cual estaría representado por una disminución del coeficiente de difusión aparente (ADC) inicial y posteriormente un aumento de señal en ADC (32). Las lesiones observadas en resonancia magnética no se corresponden con un territorio vascular, estas tienen una localización cortical. A pesar que las lesiones stroke like pueden presentarse en cualquier localización, suelen ser más frecuentes en lóbulos parietales, temporales y occipitales. Pueden existir cambios en sustancia gris profunda (núcleo caudado, globo pálido, putamen, núcleo pulvinar del tálamo y núcleo dentado del cerebelo). Se han descrito también microcalcificaciones y depósitos de calcio y hierro a nivel de núcleos basales. La espectroscopia por resonancia magnética detecta una amplia gama de metabolitos que podrían modificarse en enfermedades metabólicas, describiéndose que la disminución de $\mathrm{N}$ acetil aspartato (NAA) asociado a un incremento en el pico de lactato sería útil en el diagnóstico de pacientes con MELAS (32).

Electromiografía y velocidad de conducción: En pacientes con enfermedades mitocondriales se ha descrito neuropatía axonal, desmielinizante o mixta. No se ha determinado si la neuropatía es causada directamente por disfunción mitocondrial o por mecanismos patogénicos secundarios a la deficiencia de la cadena respiratoria. En la mayoría de los estudios en pacientes con síndrome de MELAS se ha encontrado que la polineuropatía es de tipo axonal, siendo los hombres los más susceptibles a presentarla. $(18,19)$.

Ácido láctico: La presencia de hiperlactacidemia se considera un síntoma cardinal, aunque inespecífico de MELAS. Los valores de lactato se pueden encontrar elevados en sangre y en LCR en la mayoría de los casos (1).
Biopsia muscular: El examen histológico muestra fibras musculares vacuoladas dispersas con un borde transparente con la tinción hematoxilina-eosina. Con la tinción tricrómica de Gomori, las fibras musculares afectadas se ven como fibras rojo-rasgadas (FRR) debido a la proliferación mitocondrial por debajo de la membrana plasmática. Las FRR están presentes en muchas otras enfermedades mitocondriales; sin embargo, en MELAS estas se tiñen positivamente con tinción citocromo oxidasa (COX) a diferencia de otras enfermedades mitocondriales que no reaccionan con $\operatorname{COX}(1,19)$.

\section{Estudio genético molecular}

Las variantes patogénicas asociadas a MELAS (tabla 4), se detectan en ADN mitocondrial (MtDNA) extraído de leucocitos de individuos afectados. La heteroplasmia, característica de las enfermedades mitocondriales, puede generar una distribución variable del mtDNA, por lo que las variantes podrían solo detectarse en otros tejidos como mucosa bucal, sedimento urinario o mucho más consistentemente en musculo esquelético (22,33). La recomendación es realizar estudio genético en ADN mitocondrial extraido de al menos dos diferentes tejidos.

La aproximación diagnóstica molecular más adecuada dependerá de lo característico del fenotipo de MELAS. Si el caso tiene signos clínicos típicos de MELAS, se recomienda estudio molecular de un genespecifico, para las variantes m.3243A $>$ G, y en caso negativo para las variantes m.3271T $>\mathrm{C}, 3252 \mathrm{~A}>\mathrm{G}$ (gen $M T$-TL1) y m.13513G > A (gen MT-ND5); también se puede realizar panel de genes mitocondriales o secuenciación completa de genoma mitocondrial. En los casos de fenotipos no característicos o complejos se recomienda estudios basados en panel de genes, exoma o genoma completo (1). 
Aguirre-Quispe W, et al.

Tabla 4. Genes y variantes genotípicas asociadas a MELAS

\begin{tabular}{|c|c|c|}
\hline $\begin{array}{c}\text { Porcentaje de personas } \\
\text { afectadas }\end{array}$ & $\begin{array}{c}\text { Cambio de nucleótidos del } \\
\text { ADN mitocondrial }\end{array}$ & Gen \\
\hline$\sim 80 \%$ & m. $3243 A>G$ & \multirow{6}{*}{$M T-T L 1$} \\
\hline$<10 \%$ & $\mathrm{~m} \cdot 3271 \mathrm{~T}>\mathrm{C}$ & \\
\hline \multirow[t]{12}{*}{$<5 \%$} & $\mathrm{~m} .3252 \mathrm{~A}>\mathrm{G}$ & \\
\hline & m.3291T $>C$ & \\
\hline & m.3256C $>$ T & \\
\hline & m.3260A $>G$ & \\
\hline & $\mathrm{m} .583 \mathrm{G}>\mathrm{A}$ & $M T-T F$ \\
\hline & $\mathrm{m} .1642 \mathrm{G}>\mathrm{A}$ & \multirow{2}{*}{$M T-T V$} \\
\hline & m.1644G $>$ A & \\
\hline & $\mathrm{m} .4332 \mathrm{G}>\mathrm{A}$ & $M T-T Q$ \\
\hline & $\mathrm{m} .5521 \mathrm{G}>\mathrm{A}$ & $M T-T W$ \\
\hline & m.5814A>G & $M T-T C$ \\
\hline & $\mathrm{m} \cdot 7512 \mathrm{~T}>\mathrm{C}$ & MT-TS1 \\
\hline & m. $12207 \mathrm{G}>\mathrm{A}$ & $M T-T S 2$ \\
\hline \multirow{11}{*}{ Raro } & $\mathrm{m} .12146 \mathrm{~A}>\mathrm{G}$ & \multirow{2}{*}{ MT-TL2 } \\
\hline & m.12299A $>C$ & \\
\hline & $\mathrm{m} .8316 \mathrm{~T}>\mathrm{C}$ & \multirow{2}{*}{$M T-T K$} \\
\hline & $\mathrm{m} .8296 \mathrm{~A}>\mathrm{G}$ & \\
\hline & m. $12147 \mathrm{G}>\mathrm{A}$ & $M T-T H$ \\
\hline & $\mathrm{m} .3481 \mathrm{G}>\mathrm{A}$ & \multirow{4}{*}{$M T-N D 1$} \\
\hline & $\mathrm{m} .3697 \mathrm{G}>\mathrm{A}$ & \\
\hline & m.3946G $>A$ & \\
\hline & m.3949T $>C$ & \\
\hline & m.7023G $>A$ & MT-CO2 \\
\hline & m.9957T $>C$ & MT-CO3 \\
\hline \multirow[t]{5}{*}{$<10 \%$} & m. $13513 \mathrm{G}>\mathrm{A}$ & \multirow{6}{*}{ MT-ND5 } \\
\hline & m.12770A $>$ G & \\
\hline & m. $13042 \mathrm{G}>\mathrm{A}$ & \\
\hline & m. $13084 \mathrm{~A}>\mathrm{T}$ & \\
\hline & m.13514A $>G$ & \\
\hline \multirow{4}{*}{ Raro } & m.13528A $>G$ & \\
\hline & m. $14453 \mathrm{G}>\mathrm{A}$ & MT-ND6 \\
\hline & m.14787delTTAA & \multirow{2}{*}{$M T-C Y B$} \\
\hline & $\mathrm{m} .14864 \mathrm{~T}>\mathrm{C}$ & \\
\hline
\end{tabular}

Tomado y adaptado de El-Hattab et al, 2018 (1) 


\section{Diagnóstico diferencial}

El cuadro clínico de MELAS se superpone con diversas enfermedades mitocondriales como síndrome de Kearns Sayre, MERRF y síndrome de Leigh.

El diagnóstico diferencial de los episodios de stroke like en personas jóvenes incluye: enfermedad cardíaca, enfermedades carotídeas o vertebrales, enfermedad de células falciformes, vasculopatías, discrasias de lipoproteínas, trombosis venosa, enfermedad de moyamoya, migraña complicada, enfermedad de Fabry y homocistinuria.

También se ha reportado fenotipos similares a MELAS asociados a variantes en genes nucleares como MRM2 (34), FASTKD2 (35) y POLG (36).

\section{MANEJO INTEGRAL Y MULTIDISCIPLINARIO}

Todo paciente con enfermedad de MELAS debe tener un abordaje integral y multidisciplinario. A la fecha no hay tratamiento farmacológico específico para MELAS. Sin embargo, se utilizan algunos fármacos antioxidantes como Coenzima Q10, L-Carnitina y creatina. Actualmente hay 3 ensayos clínicos en fase I y II que se encuentran evaluando intervenciones como L-Citrulina y Glutamina oral para pacientes con MELAS (www.clinicaltrials.gov).

La coenzima Q es utilizada en el síndrome de MELAS ya que facilita la transferencia de electrones del complejo I y II al complejo III de la CTE y la estabiliza al proveer protección antioxidante. Algunos estudios han demostrado un efecto beneficioso en la debilidad muscular, fatigabilidad y niveles de lactato (37). La dosis recomendada en adultos es de $200-400$ $\mathrm{mg} /$ día, con dosis máxima de $600 \mathrm{mg} /$ día. La dosis pediátrica recomendada es $3.4-10 \mathrm{mg} /$ día (nivel de evidencia bajo) (38).

La L-carnitina ha sido utilizada debido a que se ha descrito una deficiencia secundaria en algunos trastornos mitocondriales como MELAS, siendo su función el transporte de ácidos grasos de cadena larga a la matriz mitocondrial para la $\beta$-oxidación; sin embargo, actualmente no se recomienda su uso prolongado debido al riesgo de ateroesclerosis. $\mathrm{La}$ $\mathrm{L}$-carnitina se puede administrar en dosis de $3 \mathrm{~g}$ diarios en tres dosis divididas para adultos y $100 \mathrm{mg} / \mathrm{kg} /$ día para niños en tres dosis divididas ( nivel de evidencia bajo) (38).
La creatina monohidrato también se ha utilizado en el tratamiento de MELAS aunque con poca evidencia. Se ha documentado cierta mejoría en la fuerza muscular luego de actividad aeróbica y anaeróbica en pacientes con trastornos mitocondriales, así como también una leve mejoría en las crisis epilépticas. Aunque se debe tener en cuenta sus efectos adversos en la función renal, sobretodo en pacientes con la variante m.3243A> G. En adultos se recoemienda una dosis de carga de 20 $\mathrm{g} /$ día por 2 semanas y una dosis de mantenimiento de 2-5 g/día. En niños se utiliza a una dosis de 80-350 $\mathrm{mg} / \mathrm{kg} /$ día (38) (nivel de evidencia bajo)

Para el tratamiento de los episodios stroke like se recomienda L-arginina. Durante el episodio agudo se recomienda administrar un bolo de arginina intravenosa (500 $\mathrm{mg} / \mathrm{kg}$ para niños o $10 \mathrm{~g} / \mathrm{m} 2$ de superficie corporal para adultos). L-arginina se evaluó en un ensayo clínico abierto de fase 3 , en el cual la presentación oral demostró eficacia para extender la fase interictal y disminuir la incidencia y severidad del episodio stroke like. L-arginina intravenosa también mejoró las tasas de cefalea, náuseas y vómitos, alteración de la conciencia y alteración visual (nivel de evidencia moderado) (39). La taurina, un $\beta$-aminoácido que está ausente en células derivadas de pacientes con MELAS asociadas a la variante $\mathrm{m} .3243 \mathrm{~A}>\mathrm{G}$ o m.3271T $>\mathrm{C}$, es otro tratamiento que ha sido evaluado en un pequeño ensayo clínico de fase 3, a una dosis de 9 y 12 g día, que demostró eficacia en la reducción de la recurrencia de episodios stroke like (nivel de evidencia moderado) (40).

Para los episodios de crisis epiléptica se recomienda el manejo habitual de anticonvulsivantes, evitando el uso de ácido valproico, debido a que puede alterar la membrana mitocondrial induciendo cambios de despolarización paroxística, así como la alteración en la actividad de bombeo de protones del complejo IV (citocromo c oxidasa) en la cadena respiratoria, estos cambios pueden precipitar aún más la sintomatología de los trastornos mitocondriales que de por si presentan una deficiencia de citocromo c oxidasa (41). Otros anticonvulsivantes no recomendados son: carbamazepina, fenitoína, fenobarbital y topiramato. Los anticonvulsivantes que han mostrado menor riesgo de toxicidad mitocondrial y adecuado balance riesgo beneficio son levetiracetam, zonisamide , lamotrigina y gabapentina. Asimismo, se recomienda evitar el uso o consumo de: metformina debido al mayor riesgo de desarrollar acidosis láctica, antibióticos aminoglucósidos y linezolid por el 
riesgo de precipitar la insuficiencia mitocondrial y una acidosis láctica(42), cigarrillos y alcohol por el incremento del estrés oxidativo(41).

Los pacientes MELAS deben tener evaluaciones por algunas especialidades médicas por riesgo de complicaciones sistémicas. Se recomienda manejo por cardiología para las complicaciones cardiacas como la miocardiopatía y el síndrome de Wolff-ParkinsonWhite; manejo endocrinológico para el control de la diabetes; evaluaciones por otorrinolaringología en los casos de hipoacusia, manejo nutricional para establecer una dieta adecuada en estos pacientes; evaluaciones psiquiátricas periódicas en pacientes que cursan con cuadros depresivos, así como asesoramiento genético individual y familiar adecuado (1).

El asesoramiento genético debe proporcionar información precisa sobre el pronóstico de las personas afectadas y el riesgo de recurrencia para otros miembros de la familia. La sesión también debe informar sobre consecuencias de la enfermedad en el paciente y la familia sobre opciones reproductivas y otras decisiones médicas y personales de vida. Se recomienda la evaluación y asesoramiento para todos los miembros de la familia, afectados y no afectados. En las enfermedad mitocondriales como MELAS, es importante comunicar a la familia que esta enfermedad se transmite por linea matrilineal; es por ello que la madre del paciente es usualmente portadora de la variante patogénica y puede tener o no tener síntomas, aunque hay casos de variantes genéticas mitocondriales de novo. Todos los hijos de una madre portadora de variantes patogénicas de MELAS heredan esta variante; sin embargo, pueden o no desarrollar síntomas. Es por ello que la predicción de aparición de síntomas basado en pruebas genéticas no es posible (43).

Agradecimiento: Agradecemos al equipo multidisciplinario del servicio de Neurogenética del Instituto Nacional de Ciencias Neurológicas por el soporte logístico y asesoramiento temático para esta revisión.

\section{Correspondencia:}

Mario Cornejo-Olivas

Jr. Ancash 1271, Barrios Altos, Lima, Peru, 15003

Teléfono. 5114117779

Correo electrónico: mario.cornejo.o@incngen.org.pe

\section{REFERENCIAS BIBLIOGRAFICAS}

1. El-Hattab AW, Almannai M, Scaglia F. MELAS. En: Adam MP, Ardinger HH, Pagon RA, Wallace SE, Bean LJ, Mirzaa G, et al., editores. GeneReviews ${ }^{\circledR}$. Seattle (WA): University of Washington, Seattle; 2018. (Citado el 1 de agosto de 2021). Disponible en: http://www.ncbi.nlm.nih.gov/books/NBK1233/

2. El-Hattab AW, Adesina AM, Jones J, Scaglia F. MELAS syndrome: Clinical manifestations, pathogenesis, and treatment options. Mol Genet Metab. 2015;116(1-2):4-12.

3. Iizuka T, Sakai F. Pathogenesis of stroke-like episodes in MELAS: analysis of neurovascular cellular mechanisms. Curr Neurovasc Res. 2005;2(1):29-45.

4. Hirano M, Ricci E, Koenigsberger MR, Defendini R, Pavlakis SG, DeVivo DC, et al. Melas: an original case and clinical criteria for diagnosis. Neuromuscul Disord NMD. 1992;2(2):125-35.

5. Pavlakis SG, Phillips PC, DiMauro S, De Vivo DC, Rowland LP. Mitochondrial myopathy, encephalopathy, lactic acidosis, and strokelike episodes: a distinctive clinical syndrome. Ann Neurol. 1984;16(4):481-8.

6. Uusimaa J, Moilanen JS, Vainionpää L, Tapanainen P, Lindholm $P$, Nuutinen $M$, et al. Prevalence, segregation, and phenotype of the mitochondrial DNA $3243 \mathrm{~A}>\mathrm{G}$ mutation in children. Ann Neurol. 2007;62(3):278-87.

7. Majamaa K, Moilanen JS, Uimonen S, Remes AM, Salmela PI, Kärppä M, et al. Epidemiology of A3243G, the mutation for mitochondrial encephalomyopathy, lactic acidosis, and strokelike episodes: prevalence of the mutation in an adult population. Am J Hum Genet. 1998;63(2):447-54.

8. Chinnery PF, Johnson MA, Wardell TM, SinghKler R, Hayes C, Brown DT, et al. The epidemiology of pathogenic mitochondrial DNA mutations. Ann Neurol. 2000;48(2):188-93.

9. Manwaring N, Jones MM, Wang JJ, Rochtchina E, Howard C, Mitchell P, et al. Population prevalence of the MELAS A3243G mutation. Mitochondrion. 2007;7(3):230-3.

10. Yatsuga S, Povalko N, Nishioka J, Katayama K, Kakimoto N, Matsuishi T, et al. MELAS: a nationwide prospective cohort study of 96 patients in Japan. Biochim Biophys Acta. 2012;1820(5):619-24.

11. Coelho-Miranda L, Playan A, Artuch R, et al. Encefalomiopatía mitocondrial, acidosis láctica y accidentes cerebrovasculares (MELAS) en edad pediátrica con la mutación A3243G en el gen del ARNtLeu(UUR) del ADN mitocondrial. Rev Neurol. 2000;31:804-811. DOI: 10.33588/rn.3109.2000119 
12. Murad M, Sultan S, Haffar S, Bazebachi F. Methodological quality and synthesis of case series and case reports. BMJ Evidence-Based Medicine. DOI: 10.1136/bmjebm-2017-110853

13. Wong L-JC. Pathogenic mitochondrial DNA mutations in protein-coding genes. Muscle Nerve. 2007; 36(3):279-93.

14. King MP, Koga Y, Davidson M, Schon EA. Defects in mitochondrial protein synthesis and respiratory chain activity segregate with the tRNA(Leu(UUR)) mutation associated with mitochondrial myopathy, encephalopathy, lactic acidosis, and strokelike episodes. Mol Cell Biol. 1992;12(2):480-90.

15. El-Hattab AW, Hsu JW, Emrick LT, Wong L-JC, Craigen WJ, Jahoor F, et al. Restoration of impaired nitric oxide production in MELAS syndrome with citrulline and arginine supplementation. Mol Genet Metab. 2012;105(4):607-14.

16. El-Hattab AW, Emrick LT, Craigen WJ, Scaglia F. Citrulline and arginine utility in treating nitric oxide deficiency in mitochondrial disorders. Mol Genet Metab. 2012;107(3):247-52.

17. El-Hattab AW, Emrick LT, Chanprasert S, Craigen WJ, Scaglia F. Mitochondria: role of citrulline and arginine supplementation in MELAS syndrome. Int J Biochem Cell Biol. 2014;48:85-91.

18. Desquiret-Dumas V, Gueguen N, Barth M, Chevrollier A, Hancock S, Wallace DC, et al. Metabolically induced heteroplasmy shifting and l-arginine treatment reduce the energetic defect in a neuronal-like model of MELAS. Biochim Biophys Acta. 2012;1822(6):1019-29.

19. Sproule DM, Kaufmann P. Mitochondrial encephalopathy, lactic acidosis, and strokelike episodes: basic concepts, clinical phenotype, and therapeutic management of MELAS syndrome. Ann N Y Acad Sci. 2008;1142:133-58.

20. Sunde K, Blackburn PR, Cheema A, Gass J, Jackson J, Macklin S, et al. Case report: 5 year follow-up of adult late-onset mitochondrial encephalomyopathy with lactic acid and stroke-like episodes (MELAS). Mol Genet Metab Rep. 2016;9:94-7.

21. Hirano M, Pavlakis SG. Mitochondrial myopathy, encephalopathy, lactic acidosis, and strokelike episodes (MELAS): current concepts. J Child Neurol. 1994;9(1):4-13.

22. Jeppesen TD, Schwartz M, Frederiksen AL, Wibrand F, Olsen DB, Vissing J. Muscle phenotype and mutation load in 51 persons with the $3243 \mathrm{~A}>\mathrm{G}$ mitochondrial DNA mutation. Arch Neurol. 2006;63(12):1701-6.

23. Finsterer J, Zarrouk-Mahjoub S. Focal and Generalized Seizures May Occur in Mitochondrial Encephalomyopathy, Lactic Acidosis, and Strokelike Episodes (MELAS) Patients. J Child Neurol. 2015;30(11):1553-4.

24. Chen S, Chen X, Zhang Z, Quan L, Kuang S,
Luo X. MRI findings of cerebral cryptococcosis in immunocompetent patients. J Med Imaging Radiat Oncol. 2011;55(1):52-7.

25. Kärppä M, Syrjälä P, Tolonen U, Majamaa K. Peripheral neuropathy in patients with the $3243 \mathrm{~A}>\mathrm{G}$ mutation in mitochondrial DNA. J Neurol. 2003;250(2):216-21.

26. Kaufmann P, Pascual JM, Anziska Y, Gooch CL, Engelstad K, Jhung S, et al. Nerve conduction abnormalities in patients with MELAS and the A3243G mutation. Arch Neurol. 2006;63(5):746-8.

27. Sproule DM, Kaufmann P, Engelstad K, Starc TJ, Hordof AJ, De Vivo DC. Wolff-Parkinson-White syndrome in Patients With MELAS. Arch Neurol. 2007;64(11):1625-7.

28. Fujii A, Yoneda M, Ohtani M, Nakagawa H, Kumano T, Hayashi K, et al. Gastric dysmotility associated with accumulation of mitochondrial A3243G mutation in the stomach. Intern Med Tokyo Jpn. 2004;43(12):1126-30.

29. Maassen JA, 'T Hart LM, Van Essen E, Heine RJ, Nijpels G, Jahangir Tafrechi RS, et al. Mitochondrial diabetes: molecular mechanisms and clinical presentation. Diabetes. 2004;53 Suppl 1:S103-109.

30. Anglin RE, Garside SL, Tarnopolsky MA, Mazurek MF, Rosebush PI. The psychiatric manifestations of mitochondrial disorders: a case and review of the literature. J Clin Psychiatry. 2012;73(4):506-12.

31. Kim IO, Kim JH, Kim WS, Hwang YS, Yeon KM, Han MC. Mitochondrial myopathy-encephalopathylactic acidosis-and strokelike episodes (MELAS) syndrome: CT and MR findings in seven children. AJR Am J Roentgenol. 1996;166(3):641-5.

32. Malhotra K, Liebeskind DS. Imaging of MELAS. Curr Pain Headache Rep. 2016;20(9):54.

33. Chinnery PF, Howell N, Lightowlers RN, Turnbull DM. Molecular pathology of MELAS and MERRF. The relationship between mutation load and clinical phenotypes. Brain J Neurol. 1997;120 ( Pt 10):171321.

34. Garone C, D'Souza AR, Dallabona C, Lodi T, RebeloGuiomar P, Rorbach J, et al. Defective mitochondrial rRNA methyltransferase MRM2 causes MELAS-like clinical syndrome. Hum Mol Genet. 2017;26(21):4257-66.

35. Yoo DH, Choi Y-C, Nam DE, Choi SS, Kim JW, Choi B-O, et al. Identification of FASTKD2 compound heterozygous mutations as the underlying cause of autosomal recessive MELAS-like syndrome. Mitochondrion. 2017; 35:54-8.

36. Cheldi A, Ronchi D, Bordoni A, Bordo B, Lanfranconi $\mathrm{S}$, Bellotti $\mathrm{MG}$, et al. POLG1 mutations and stroke like episodes: a distinct clinical entity rather than an atypical MELAS syndrome. BMC Neurol. 2013;13:8.

37. Glover EI, Martin J, Maher A, Thornhill RE, Moran GR, Tarnopolsky MA. A randomized trial of 
coenzyme Q10 in mitochondrial disorders. Muscle Nerve. 2010;42(5):739-48.

38. Scaglia F, Northrop JL. The Mitochondrial Myopathy Encephalopathy, Lactic Acidosis with Stroke-Like Episodes (MELAS) Syndrome. CNS Drugs. 2006;20(6):443-64.

39. Koga Y, Povalko N, Inoue E, Nakamura H, Ishii A, Suzuki Y, et al. Therapeutic regimen of L-arginine for MELAS: 9-year, prospective, multicenter, clinical research. J Neurol. 2018;265(12):2861-74.

40. Ohsawa Y, Hagiwara H, Nishimatsu S-I, Hirakawa A, Kamimura N, Ohtsubo $\mathrm{H}$, et al. Taurine supplementation for prevention of stroke-like episodes in MELAS: a multicentre, open-label, 52-week phase III trial. J Neurol Neurosurg Psychiatry. 2019;90(5):529-36.
41. Lin C-M, Thajeb P. Valproic acid aggravates epilepsy due to MELAS in a patient with an A3243G mutation of mitochondrial DNA. Metab Brain Dis. 2007;22(1):105-9.

42. Cope TE, McFarland R, Schaefer A. Rapidonset, linezolid-induced lactic acidosis in MELAS. Mitochondrion. 2011;11(6):992-3.

43. Poulton J, Finsterer J, Yu-Wai-Man P. Genetic Counselling for Maternally Inherited Mitochondrial Disorders. Mol Diagn Ther. 2017;21(4):419-29.

Recibido: 24/08/2021

Aceptado: 14/12/2021 